\title{
Influence of grain growth on the structural properties of the nanocrystalline $\mathbf{G d}_{2} \mathbf{T i}_{2} \mathrm{O}_{7}$
}

\author{
P. K. Kulriya, Tiankai Yao, Spencer Michael Scott, Sonal Nanda, JieLian* \\ Department of Mechanical, Aerospace \& Nuclear Engineering, Rensselaer Polytechnic Institute, \\ Troy, NY 12160, USA
}

*Corresponding author; Email: lianj@ rpi.edu; Office: 518-276-6081; Fax: 518-276-6025

\begin{abstract}
The microstructure evolution and grain growth kinetics of the nanocrystalline $\mathrm{Gd}_{2} \mathrm{Ti}_{2} \mathrm{O}_{7}$ drastically affect its properties and functionalities as thermal barrier coatings and nuclear waste forms for actinide incorporation. Here, we report the synthesis of the dense nano-sized $\mathrm{Gd}_{2} \mathrm{Ti}_{2} \mathrm{O}_{7}$ by high energy ball milling (HEBM), and spark plasma sintering (SPS), and also investigated the isothermally annealing induced grain coarsening and structural properties variations. Asprepared nano powder (D 60 nm) by HEBM exhibited an amorphous nature, which was consolidated to a dense single phase crystalline pyrochlore nano-ceramic ( $\mathrm{D} \sim 120 \pm 10 \mathrm{~nm}$ ) by SPS sintering at $1200{ }^{\circ} \mathrm{C}$. Isothermal annealing was performed at different temperatures $\left(1300{ }^{\circ} \mathrm{C}\right.$ - $1500{ }^{\circ} \mathrm{C}$ ) with holding time varying from 0.5 to 8 hours, and the pyrochlore phase is stable with no indication of a transformation into a defect fluorite structure. A rapid initial grain growth was observed which increased with temperature and annealing durations due to the large drive force of the curvature-driven grain coarsening of the nano-ceramics, and grain growth saturates at longer durations. The calculated value of the time constant and activation energy for the nanocrystalline $\mathrm{Gd}_{2} \mathrm{Ti}_{2} \mathrm{O}_{7}$ were $0.52 \pm 0.02$ and $240 \pm 20 \mathrm{~kJ} / \mathrm{mol}(\sim 2.48 \mathrm{eV})$, respectively. The enhanced grain growth kinetics with a lower value of activation energy can be explained by the effect of fast diffusion across the grain boundaries for dense nanoceramics.
\end{abstract}




\section{Introduction}

The fundamental mechanism for the grain growth has been extensively investigated due to the significance of microstructures on the optimization of the physical properties, and the design of advanced materials.[1-4] In the grain growth process, the average grain size of the aggregate crystallites increases resulting in a decrease in the system free energy by reducing the total grain boundary area.[5] Grain growth can be divided into two categories namely normal grain growth, and abnormal or fast grain growth. The normal grain growth (with a high grain boundary activation energy) is considered a thermally-activated microstructure evolution phenomenon, in which curvature-driven grain boundary migration and grain-rotation occur. Micro-crystalline materials exhibit normal grain growth process. In case of abnormal grain growth processes, few grains grow at a much faster rate than others due to high atomic mobility at the grain boundaries. This effect is predominately detected due to presence of impurity atoms or defects at the interface. Grain growth with very low activation energies was also observed during the synthesis of nanocrystalline (hereafter referred as nc-) materials using various techniques such as sintering, pulsed laser deposition, and spray pyrolysis.[6, 7] Recently, low temperature irradiation induced rapid grain growth in nanocrystalline $(<10 \mathrm{~nm})$ ceria $[2,8]$ and zirconia was described by the disorder driven mechanism. [9] Elizabeth et al., reported stagnation of grain growth in pure materials due to the smooth grain boundary. [1] Increase in the grain size of nanostructured yttria-stabilized tetragonal zirconia (YSZ) on high temperature annealing ( $1100{ }^{\circ} \mathrm{C}$ for 300 hours) was explained by the grain coalescence mechanism. [10-12]

$\mathrm{Gd}_{2} \mathrm{Ti}_{2} \mathrm{O}_{7}$ is a technologically important material that exhibits highly attractive chemical, structural and physical properties for various applications such as catalysts, fast ion conductors, and high temperature thermal barrier coatings. $\mathrm{Gd}_{2} \mathrm{Ti}_{2} \mathrm{O}_{7}$ is also a potential waste forms for 
immobilization of actinides (particularly, $\mathrm{U}$ and Pu from dismantled nuclear warheads) in which actinides can be incorporated in Gd sublattice in the pyrochlore structure, and was thereby selected as a model system for the present study. [13-16] Due to the high radiation resistance of some compositions like $\mathrm{Gd}_{2} \mathrm{Zr}_{2} \mathrm{O}_{7}$, pyrochlores are also considered as inert fuel matrix or potential host phases for transmutation of actinides. The microstructural evolution and grain growth kinetics will have profound impacts on the phase, structure and physical properties of materials and thus their potential applications. For example, nanostructured $\mathrm{Gd}_{2} \mathrm{Ti}_{2-}$ ${ }_{x} \mathrm{Zr}_{\mathrm{x}} \mathrm{O}_{7}$ pyrochlore displays enhanced radiation tolerance with reduced grain size in which high density of grain boundaries and interfaces can behave as effective sinks for defect recovery. [1719] Nanostructured ceramics can also display enhanced mechanical properties with grain boundaries to pin dislocation motions. For nuclear fuel applications, radiation-induced grain subdivision may occur, e.g., in the rim of oxide fuels, leading to the formation of a high burn-up structure with micron-sized pores embedded into anano-crystalline matrix. [20-21] The grain coarsening of the nanocrystalline matrix and its growth kinetics will impact thermal-mechanical properties and thus fuel performance significantly.

In this study, dense nc- $\mathrm{Gd}_{2} \mathrm{Ti}_{2} \mathrm{O}_{7}$ was fabricated using advanced nano-ceramic fabrication techniques including HEBM and SPS. Scanning electron microscopy (SEM), along with X-ray diffraction (XRD), and Raman spectroscopy were used to elucidate the influence of grain growth on the structural properties of the nanocrystalline ceramic. The grain growth time constant and activation energy were determined and results were interpreted in the frame work of the elimination of inter particle pores by the densification, curvature-driven grain boundary migration, and micro-strain induced structural modifications.

\section{Experimental Procedures}




\subsection{Synthesis of nano-crystalline $\mathrm{Gd}_{2} \mathrm{Ti}_{2} \mathrm{O}_{7}$}

Starting reagents used in this work were $\mathrm{Gd}_{2} \mathrm{O}_{3}$ (Sigma-Aldrich, 99.9\%), and $\mathrm{TiO}_{2}$ (Sigma-Aldrich, 99.9\%). In order to evaporate water impurity, reagents were calcinated at the temperature of $800{ }^{\circ} \mathrm{C}$ for 12 hours in the air atmosphere followed by natural furnace cooling at the room temperature. Appropriate amounts of the constituent oxides as required by stoichiometry $\left(1 \mathrm{Gd}_{2} \mathrm{O}_{3}: 2 \mathrm{TiO}_{2}\right)$, were weighed out, mixed with ethanol, and placed in a zirconia bowl together with $1 \mathrm{~mm}$ diameter zirconia balls as the milling media. In a typical experiment, a $10 \mathrm{~g}$ batch of reactants was milled in air using a HEBM system (Fritsch, Pulverisette 7, IdarOberstein, Germany). The HEBM milling was done for 80 cycles with each cycle of about 30 minutes at the speed of $500 \mathrm{rpm}$. After each cycle, milling process was stopped for 10 minutes to avoid the excessive heating. The temperature during milling was monitored and temperature of the reactant was increased to about $45{ }^{\circ} \mathrm{C}$. Samples were taken out after milling time of 20,30 and 40 hours, then dried it, and characterized by XRD using a Philips X'pert diffractometer (Nifiltered $\mathrm{CuK}_{\alpha}$ radiation with $\lambda=1.5418 \AA$ ). The diffraction patterns were recorded in the $2 \theta$ range varying from $10^{\circ}-80^{\circ}$ angle at an increment of $0.013^{\circ}$ with scan speed of $0.5^{\circ} \mathrm{min}^{-1}$.

\subsection{Sintering, and annealing of nano-crystalline $\mathrm{Gd}_{2} \mathrm{Ti}_{2} \mathrm{O}_{7}$}

SPS was used for the preparation of nano-phase ceramic (Dr. Sinter® SPS-211 Lx system). SPS allows for inter-particle pores to be eliminated by passing high electrical current in a compact powder geometry. For each sintering experiment, nano powders $(\sim 1 \mathrm{~g})$ were loaded into a graphite die (10 $\mathrm{mm}$ diameter). To improve the conduction between die and powders as well as proper fitting of nano powders into the assembly, it was enveloped in a graphite paper of $0.20 \mathrm{~mm}$ thick. SPS was carried out at a peak temperature of $1200{ }^{\circ} \mathrm{C}$ and pressure of $40 \mathrm{MPa}$ for 
a duration of 20 minutes. In order to avoid the cracking of the pellet, post-sintering annealing of the sample was performed at the temperature of $1100{ }^{\circ} \mathrm{C}$ for 30 minutes. The temperature was measured by a pyrometer focused on the outside wall of the graphite die and it was automatically regulated above $600^{\circ} \mathrm{C}$. All specimens were subsequently annealed in air at $800^{\circ} \mathrm{C}$ for 12 hours to remove the carbon contaminations present from the graphite dies. The density of the assintered pellets was measured using Archimedes' principle to be above $94 \%$ of the theoretical density. After that, top surfaces of the pellets were polished with diamond lapping films. The mirror-like polished samples were annealed at the temperature of $1300{ }^{\circ} \mathrm{C}, 1400{ }^{\circ} \mathrm{C}$, and $1500{ }^{\circ} \mathrm{C}$ for the duration of $0.5,1,2,4$, and 8 hours, respectively. Annealing was carried out at slow heating and cooling rates of $2^{\circ}$ per minutes and $3^{\circ}$ per minutes, respectively.

\subsection{Characterization of nanocrystalline $\operatorname{Gd}_{2} \mathrm{Ti}_{2} \mathrm{O}_{7}$}

The surface morphology of the as-prepared, sintered, and annealed samples was carried out using a Carl Zeiss Supra (Jena, Germany) field emission SEM (FESEM). Before FESEM characterization, a thin layer of platinum was deposited on the fractured surface in an argon atmosphere using a Denton Sputterer (Denton Vacuum, LLC, NJ, USA). The grain size (D) was determined using a rectangular intercept procedure following ASTM E112-88 standard. [22] The average size is given by

$$
D_{t}=\sqrt{\frac{4 A}{\pi\left(N_{i}+\frac{N_{0}}{2}\right)}}
$$

Where, $\mathrm{A}$ is the area of the rectangle, $\mathrm{N}_{\mathrm{i}}$ and $\mathrm{N}_{0}$ are the number of grains in the rectangle and on the boundary of the rectangle, respectively. Few hundred of grains were counted for each data of grain size using various SEM images. The calculated value of the uncertainly is the standard 
deviation in these data. Raman spectroscopy measurements on the sintered and annealed pellets were carried out using a Renishaw Raman spectrometer equipped with an argon laser (514 nm) focused on sample surfaces with a spot size of $\sim 1 \mathrm{~mm}$.

\section{Results and discussion}

Fig. 1 shows the XRD pattern and SEM micrographs of the nano-powders milled using HEBM for 40 hours. The XRD pattern of the nano-powders indicates that the as-milled powders are amorphous. No impurity peaks from residual reagents were observed in the ball milled nanopowders, confirming that all the reagents were fully mixed. SEM images of milled samples also demonstrate a typical feature of mechanical milling of powders of micron-sized granules containing nano-sized particles (here $\sim 60 \mathrm{~nm}$ ). Fig. 2 shows the representative microstructures of the fracture surfaces of the (a) as prepared nc- $\mathrm{Gd}_{2} \mathrm{Ti}_{2} \mathrm{O}_{7}$ specimens, and annealed samples for the duration of 4 hours at (b) $1300{ }^{\circ} \mathrm{C}$, (c) $1400{ }^{\circ} \mathrm{C}$, and (d) $1500{ }^{\circ} \mathrm{C}$. In the as-sintered sample, submicron sized pores can be clearly seen at the surface, consistent with density measurement results of a $\sim 6 \%$ porosity. Porosities for the sample annealed for the duration of 4 hours at (a) $1300{ }^{\circ} \mathrm{C}$, (b) $1400{ }^{\circ} \mathrm{C}$, and (c) $1500{ }^{\circ} \mathrm{C}$, are shown in table 1 . SEM revealed that the average grain sizes were in the range of 100-120 nm, larger than that of as-milled powder samples, indicating grain growth occurs during sintering itself. Similar grain growth during synthesis process itself was also reported on the high-frequency induction heated sintering of nano-sized (58 to76 nm) $\mathrm{ZrO}_{2}\left(3 \mathrm{~mol} \% \mathrm{Y}_{2} \mathrm{O}_{3}\right)$ at $100 \mathrm{MPa}$, and $1000^{\circ} \mathrm{C}$, and obtained materials had an average grain size about $250 \mathrm{~nm}$.[23] On high temperature annealing for a duration of 4 hours [Fig. 2 (b-d)], the microstructures were composed of uniform grains with average grain sizes increased from $0.94 \pm 0.08 \mu \mathrm{m}$ to $6.46 \pm 0.25 \mu \mathrm{m}$ as annealing temperature increased from $1300{ }^{\circ} \mathrm{C}$ to $1500{ }^{\circ} \mathrm{C}$. It may be noted that upon annealing at the $1300{ }^{\circ} \mathrm{C}$, in addition to increase in grain 
size, large numbers of uniformly-distributed pores were also developed. These sub-micron sized pores formed at the grain boundaries/triple junctions as a result of the sintering of the starting assynthesized pellets, which contained aggregated crystals with a large size distribution [Fig. 2b]. When annealing temperature was further increased to $1400{ }^{\circ} \mathrm{C}$, grain size was further increased, but the density of the sub-micron sized pores was decreased. The pore size was increased due to aggregation of the nearby pores. On subsequent increase in the annealing temperature to 1500 ${ }^{\circ} \mathrm{C}$, dense grains of $\sim 10 \mu \mathrm{m}$ were formed.

To elucidate the effect of annealing time on the grain growth, Fig. 3 shows representative micrographs of the nc- $\mathrm{Gd}_{2} \mathrm{Ti}_{2} \mathrm{O}_{7}$ specimens annealed at the $1300{ }^{\circ} \mathrm{C}$ and $1500{ }^{\circ} \mathrm{C}$ for the duration of 0.5 and 8 hours. As expected, grain size increased with increase in the annealing time. It also exhibits that even for a short annealing duration $(0.5 \mathrm{~h})$, the effect of the temperature is quite significant. For detailed understanding of the effects of annealing time and temperature on the grain growth, grain size was calculated from SEM images of the different samples. The variation in the grain size with annealing time for different annealing temperatures are shown Table 2 and also plotted in Fig. 4. These results indicate that initially, the rate of grain growth was rapid, but saturated as annealing was performed for extended durations. In order to understand the grain growth kinetics in the nano-ceramic, the grain growth time constant and activation energy were calculated. Burke and Turnbull first proposed the kinetics for the grain growth in the polycrystalline materials on the basis of curvature dependent grain boundaries migration, in which atoms diffuse across and along the grain boundaries, leading to a reduction in the grain boundary area. $[24,25]$ In this formulation, grain boundary velocity was defined as a product of driving force and intrinsic mobility

$\mathrm{G}=\frac{\mathrm{dD}_{\mathrm{t}}}{\mathrm{dt}}=\Delta \mathrm{F}_{\mathrm{m}} \cdot \mathrm{M}_{\mathrm{b}} \cdot \frac{1}{\mathrm{a}}$ 
Where, ' $a$ ' is lattice parameter at the grain boundary, which is inversely proportional to the grain boundary velocity, indicates that crystal structure has a critical effect on the grain growth process; $\Delta \mathrm{F}_{\mathrm{m}}$ is the driving force which is emerged out due to difference in the free energy of materials on the both sides of a grain boundary, and given by the Gibbs-Thompson equation: $\Delta F_{m}=\frac{A \cdot \gamma \cdot V_{m}}{r}$, where $V_{m}$ is the molar volume, $\gamma$ is the grain boundary surface tension, $A$ is the constant ( 1 to 3 for spherical and cylindrical curvature), and $r$ is the radius of curvature of the grain, that is proportional to average grain diameter (D). The driving force term is specifically important for the grain growth in nano-materials due to present of large number of grain boundaries, and fast grain boundary migration is expected in case of nano-materials. Another variable in equation (1) is the grain boundary mobility $\left(\mathrm{M}_{\mathrm{b}}\right)$, which depends upon the molar entropy of the grain boundary migration, lattice constant and temperature. The grain boundary mobility can be express as $M_{b}=\frac{a^{2}}{h} \cdot e^{\left(\frac{\Delta S}{R}\right)} e^{\frac{-Q}{R T}}$, where $S$ is the molar entropy of the grain boundary migration that is the difference in entropy between activated state and ground state. The equation (1) can be further simplified by taking integration with respect to time, and can be written as:

$\frac{d D_{t}}{d t}=\frac{K}{D_{t}}$

Here, $\mathrm{K}$ is constant known as grain growth exponent and depends upon the annealing temperature. This clearly indicates that the grain growth rate $\left(\mathrm{dD}_{\mathrm{t}} / \mathrm{dt}\right)$ is related to the mean radius of grain curvature, and inversely proportional to the average grain size (D). Upon integration equation (2), yields

$\left(D_{t}\right)^{n}-\left(D_{0}\right)^{n}=K \cdot t$ 
Equation (3) is valid for grain growth kinetics in highly purity metal, and in very dense metals. In case of nano materials, present of large number of pore and grain boundary as well as higher surface to volume ratio alter the grain growth kinetics. [26] Thus, equation (3) is modified by the introduction of time exponent $(\mathrm{m})$ in the time dependent term, and grain growth kinetic law for the nano-materials can be express as

$\left(D_{t}\right)^{n}-\left(D_{0}\right)^{n}=k_{0} e^{\frac{-Q}{R T}} t^{m}$

$\ln \left[\mathrm{D}_{\mathrm{t}}^{\mathrm{n}}-\mathrm{D}_{0}^{\mathrm{n}}\right]=\ln \mathrm{k}_{0}-\frac{\mathrm{Q}}{\mathrm{R}} \cdot \frac{1}{\mathrm{~T}}+m \cdot \ln (\mathrm{t})$

Where, $D_{t}$ represents the grain size at the annealing time $t, D_{0}$ the grain size at time zero, $n$ the grain growth exponent, $\mathrm{R}$ the gas constant, $\mathrm{T}$ temperature, $\mathrm{Q}$ the activation energy for grain growth, $m$ is the time component of grain growth. Using as-prepared grain size as $G_{0}$, a good fit was obtained by taking grain growth exponent as $n=2$, indicating that rate controlling mechanism for the $n c-\mathrm{Gd}_{2} \mathrm{Ti}_{2} \mathrm{O}_{7}$ is grain boundary diffusion.

Fig. 5 (a) shows the plots of $\ln \left(\mathrm{G}_{\mathrm{t}}{ }^{\mathrm{n}}-\mathrm{G}_{0}{ }^{\mathrm{n}}\right)$ versus $\ln (\mathrm{t})$, and the slope of the linear fit of the plot between $\ln \left(\mathrm{G}_{\mathrm{t}}{ }^{\mathrm{n}}-\mathrm{G}_{0}{ }^{\mathrm{n}}\right)$ versus $\ln (\mathrm{t})$ gives the value of time component $(m)$. The average of the fitted value of the $\mathrm{m}$ is $0.52 \pm 0.02$. This shows a parabolic dependence upon the time, consistent with reported results on the nano-ceramic materials. [26] The activation energy for the grain growth was evaluated by the Arrhenius plot between the $\ln \left(\mathrm{G}_{\mathrm{t}}{ }^{\mathrm{n}}-\mathrm{G}_{0}{ }^{\mathrm{n}}\right)$ versus inverse of temperature $(1 / \mathrm{T})$, and shown in Fig. 5 (b). The slope of the curve gives activation energy for the grain growth, which is the $\sim 240 \pm 20 \mathrm{~kJ} / \mathrm{mol}$ for the nano $\mathrm{Gd}_{2} \mathrm{Ti}_{2} \mathrm{O}_{7}$. To the best of our knowledge, the activation energy for the grain growth of the bulk as well as nc- $\mathrm{Gd}_{2} \mathrm{Ti}_{2} \mathrm{O}_{7}$ is not available. So, we have compared activation energy for other ceramics and shown in Table 3. It shows that the value of activation energy fornc- $\mathrm{Gd}_{2} \mathrm{Ti}_{2} \mathrm{O}_{7}$ is lower than the reported value for other bulk ceramics calculated using either $n=2$ or 3 . $[11,27,28]$ In bulk zirconia ceramics, both grain boundary 
diffusion ( $\mathrm{n}=2$ for initial stage), and lattice diffusion ( $\mathrm{n}=3$ for final stage of sintering) were reported. [27] Temperature dependent grain growths (slow grain growth with the activation energy of $280 \mathrm{~kJ} / \mathrm{mol}$ for $\mathrm{T}<1400{ }^{\circ} \mathrm{C}$, and fast grain growth with the activation energy of 546 $\mathrm{kJ} / \mathrm{mol}$ for $\mathrm{T}>1400^{\circ} \mathrm{C}$ ) were reported for the yttria-stabilized tetragonal zirconia (YSZ). [11] In comparison to bulk ceramic materials, Clavier et al., observed a relatively-lower value of activation energy $(435 \pm 25 \mathrm{~kJ} / \mathrm{mol})$ in the $\mathrm{ThO}_{2}$, which was attributed to the development of specific surface area during grinding step. [29] If one compares time exponent and activation energy with reported values on nano-oxide materials, then the observation of relatively higher valuescould be due to bigger grain size of as-prepared $\mathrm{Gd}_{2} \mathrm{Ti}_{2} \mathrm{O}_{7}$, and higher annealing temperature. [26]

To further examine the grain growth mechanism and its influence on the structural properties, XRD and Raman spectroscopy studies were conducted. Fig. 6 displays the XRD pattern of the (a) as-sintered, as well as the samples annealed at the temperature of (b) $1300{ }^{\circ} \mathrm{C}$, (c) $1400{ }^{\circ} \mathrm{C}$, and (d) $1500{ }^{\circ} \mathrm{C}$ for the duration of 4 hours. The as-sintered sample exhibited pyrochlore superstructure with the unit cell parameter of $10.2485 \AA$ as determined from XRD patterns [indexed by a JCPDS file No. 00-023-0259]. It may be noted that peaks corresponding to the fluorite sub-cell appear under the reflection conditions ofh $+\mathrm{k}, \mathrm{k}+\mathrm{l}, \mathrm{l}+\mathrm{h}$ are a multiple of four (e.g $. \mathrm{h}+\mathrm{k}=4 \mathrm{n}, \mathrm{k}+\mathrm{l}=4 \mathrm{n}, \mathrm{l}+\mathrm{h}=4 \mathrm{n})$. [30] Since pyrochlore superstructure peaks appear due to extra conditions of allowed reflection $(h=2 n+1, h, l=2 n$, or $h, k, 1=4 n+2)$, the intensity of these peaks was very small and also consistent with reported results. [30] On high temperature anealing, increase in the intensity of peaks, as well as shifts in the diffraction peaks towards high angle were observed. The full width at half maxima (FWHM) of the peaks were significantly reduced, indicating grain growth due to high temperature anealing. The micro-strain and 
crystallite size of the as-sintered and the annealed samples were calcualted using WilliamsonHall analysis. The calcuated value of the crystallite size for the as-sintered sample as well as sample annealed at $1300{ }^{\circ} \mathrm{C}, 1400{ }^{\circ} \mathrm{C}$, and $1500{ }^{\circ} \mathrm{C}$ for 4 hours are shown in Table 1 . An increase in the crystallite size upon annealing was observed due to temperature induced grain growth. Recently, Antić et al., also reported increase in the crystallite size of $\mathrm{Eu}^{3+}$-doped $\mathrm{Gd}_{2} \mathrm{Ti}_{2} \mathrm{O}_{7}$ thin films on high temperature anealing. [31] It may be noted that the crystallite size calcuated from the XRD is smaller than grain size measured from the SEM. This is because grains are composed of more than one crystallite.The calculated value of the micro-strain in the as-sintered sample is $0.24 \%$; whereas its value are $0.09 \%, 0.11 \%, 0.13 \%$ for the samples anealed at $1300{ }^{\circ} \mathrm{C}, 1400{ }^{\circ} \mathrm{C}$, and $1500{ }^{\circ} \mathrm{C}$, respectively. It shows that micro-strain was drastically decreased on annealing at the lowest temperature because of reduction in the interparticle gap, and densification of the ceramic. When annealing temperature was subsequently increased, micro-strain was almost constant and its variation was within experimental error.

We further extended our study using Raman spectroscopy, which provided information about the structural change due to changes in the position of oxygen in the anion sublattice. Theoretically, six Raman active vibration modes $\left[\mathrm{A}_{1 \mathrm{~g}}(\mathrm{Gd}-\mathrm{O}\right.$ stretch $), \mathrm{E}_{\mathrm{g}}, 4 \mathrm{~T}_{2 \mathrm{~g}}(\mathrm{O}-\mathrm{Gd}-\mathrm{O}$ bond bending)] can be observed due to vibration in $\mathrm{O}$ present at $48 \mathrm{f}$ and $8 \mathrm{a}$ sites in the $\mathrm{Gd}_{2} \mathrm{Ti}_{2} \mathrm{O}_{7}$ pyrochlore. The most prominent Raman bands $T_{2 \mathrm{~g}}\left(310 \mathrm{~cm}^{-1}\right)$ and $\mathrm{E}_{\mathrm{g}}\left(\sim 320 \mathrm{~cm}^{-1}\right)$ emerge due to O-Gd-O bond bending. Another intense band $\mathrm{A}_{1 \mathrm{~g}}\left(520 \mathrm{~cm}^{-1}\right)$ assigned to the $\mathrm{Gd}-\mathrm{O}$ stretch, was attributed to oxygen position parameter $(\mathrm{x})$, through vibration of $48 \mathrm{f}(\mathrm{O})$ along $<100>$ cubic axes. [32-34] Other $\mathrm{T}_{2 \mathrm{~g}}$ modes were predicted at the wavenumber of $200 \mathrm{~cm}^{-1}, 450 \mathrm{~cm}^{-1}$, and 580 $\mathrm{cm}^{-1}$. Normally, Raman active modes corresponding to Ti-O stretch were not observed at lower wavenumbers because of the short bond length of Ti-O bond. 
In present study, Raman spectra of $n c-\mathrm{Gd}_{2} \mathrm{Ti}_{2} \mathrm{O}_{7}$ of the as-sintered sample, as well as samples annealed at various temperatures such as $1300{ }^{\circ} \mathrm{C}, 1400{ }^{\circ} \mathrm{C}$, and $1500{ }^{\circ} \mathrm{C}$ for a duration varying from 1 hour to 8 hours, were investigated. Representative Raman spectra for samples subjected to annealing at $1300{ }^{\circ} \mathrm{C}, 1400{ }^{\circ} \mathrm{C}$, and $1500{ }^{\circ} \mathrm{C}$ at constant time duration of 4 hours, were compared and shown in Fig. 7. In the as-sintered sample, four $\mathrm{T}_{2 \mathrm{~g}}$ modes appeared at the wavenumber of $200 \mathrm{~cm}^{-1}, 308 \mathrm{~cm}^{-1}, 320 \mathrm{~cm}^{-1}$ and $450 \mathrm{~cm}^{-1}$ due to O-Gd-O bond bending; whereas one $\mathrm{A}_{1 \mathrm{~g}}$ mode appeared at the wavenumber of $516 \mathrm{~cm}^{-1}$ due to $\mathrm{Gd}-\mathrm{O}$ stretch. The presence of theoretically-reported modes further supports XRD results for the formation of ordered pyrochlore structure of $\mathrm{Gd}_{2} \mathrm{Ti}_{2} \mathrm{O}_{7}$ in the as-sintered sample. It may be noted that Raman spectrum of the nano-sized $\mathrm{Gd}_{2} \mathrm{Ti}_{2} \mathrm{O}_{7}$ is similar to that of bulk $\mathrm{Gd}_{2} \mathrm{Ti}_{2} \mathrm{O}_{7}$, indicating that structural ordering on anion sub-lattice remained unaffected despite the change in the grain microstructure of the ceramic. In addition, a weak band at the wavenumber of $130 \mathrm{~cm}^{-1}$, and flat bands at around $675 \mathrm{~cm}^{-1}$ and $855 \mathrm{~cm}^{-1}$ were also observed. These features were also reported by the Sanju' anet al., in their high energy milled $\mathrm{Gd}_{2} \mathrm{Ti}_{2} \mathrm{O}_{7}$ pyrochlore, and attributed to the presence of small fraction of amorphous phase. [34] In higher frequency range, few vibration modes between 1000-1200 $\mathrm{cm}^{-1}$ were also observed. These peaks could be assigned to the Ti-O Raman active modes, which were expected to be at the higher frequency range due to small Ti-O distance (1.8 Ả). Upon high temperature annealing, the position of the Raman active modes remained constant with change in the annealing temperature. This confirms that $\mathrm{Gd}_{2} \mathrm{Ti}_{2} \mathrm{O}_{7}$ does not transform into a defect fluorite structure during the heating process. In case of $\mathrm{Gd}_{2} \mathrm{Ti}_{2} \mathrm{O}_{7}$, the formation enthalpy of $\Delta H_{f}=-3822.5 \pm 4.6 \mathrm{~kJ} / \mathrm{mol}$ for anti-site defects is very high. Therefore, the defect fluorite structure is not thermodynamically favored and these results are consistent with earlier reports. [35-37] 
To further elucidate the effect of annealing temperature, intensity ratio $\left(\mathrm{T}_{2 \mathrm{~g}} / \mathrm{A}_{1 \mathrm{~g}}\right)$ of prominent peaks of both modes were compared. The effect of annealing temperature on the $\mathrm{T}_{2 \mathrm{~g}} / \mathrm{A}_{1 \mathrm{~g}}$ ratio is negligible, indicating that oxygen position is not affected by the increasing in the annealing time for a particular value of annealing temperature. In order to investigate the effect of annealing duration, the Raman spectra for samples subjected to an annealing temperature of (a) $1500{ }^{\circ} \mathrm{C}$ and (b) $1300{ }^{\circ} \mathrm{C}$ for different time (1, 2, 4, and 8 hours), were compared and shown in Fig. 8. It shows that position of the Raman active modes remains same with increasing in the annealing time. The comparison of intensity ratio $\left(\mathrm{T}_{2 \mathrm{~g}} / \mathrm{A}_{1 \mathrm{~g}}\right)$ also shows that effect of annealing time is negligible. Thus, XRD along with Raman spectroscopy confirms that grain growth primarily affects long range ordering of the system by relaxation in the micro-strain and increase in the crystallite size; while the effect on the structural ordering specifically onanion lattice was not significant.

\section{Conclusions}

In summary, a systematic grain growth study was carried out on nc- $\mathrm{Gd}_{2} \mathrm{Ti}_{2} \mathrm{O}_{7}$ prepared from the spark plasma sintering of milled nano-powders, and subsequently annealed at the different temperatures and time durations. The $\mathrm{Gd}_{2} \mathrm{Ti}_{2} \mathrm{O}_{7}$ grains grow gradually with the increasing of annealing time and temperature. The grain growth time component $(0.52 \pm 0.02)$ and activation energy $(240 \pm 20 \mathrm{~kJ} / \mathrm{mol})$ for the grain growth have been estimated. Our results showed that nanocrystalline grain growth kinetics is different than microcrystalline materials. Structural studies confirmed that grain growth primarily leads to relaxation in the micro-strain and increase in the crystallite size; while the effect on anion lattice was not detected. The results of the present study on the understanding of grain growth mechanism in the intermediate size range and its 
effects on the structural properties could be useful in designing and tailoring the ceramics for the energy applications.

\section{Acknowledgement}

This work was supported as part of the WastePD, an Energy Frontier Research Center funded by the U.S. Department of Energy, Office of Science, Basic Energy Sciences under Award \# DESC0016584. One of the authors (P. K. Kulriya) acknowledges the United-states India Education foundation (USIEF) for awarding Fulbright Post Doctorate Fellowship (Award No. 2051/FNPDR/2015), and Dr. D. Kanjilal, Director, Inter University Accelerator Centre, New Delhi for granting study leave.

\section{References}

[1] E. A. Holm, S. M. Foiles, Science 328 (2010) 1138-1140.

[2] D. S. Aidhy, Y. Zhang, W. J. Weber, Scripta Materialia 83 (2014) 9-12.

[3] D. Fan, L.-Q. Chen, Acta Materialia 45 (1997) 611-622.

[4] W. W. Mullins, J. Appl. Phys. 27 (1956) 900-904.

[5] M. S. Veshchunov, Materials 2 (2009)1252-1287.

[6] J. L.M. Rupp, A. Infortuna, L. J. Gauckler, Acta Materialia 54 (2006) 1721-1730.

[7] J. L. M. Rupp, B. Scherrer,A. S. Harvey, L. J. Gauckler, Adv. Funct. Mater. 19(2009)27902799.

[8]Y. Zhang, P. D. Edmondson, T. Varga, S. Moll, F. Namavar, C. Lan, W. Weber, J. Physical Chemistry Chemical Physics 13 (2011) 11946-11950. 
[9] Y. Zhang, W. Jiang, C. Wang, F. Namavar, P.D. Edmondson, Z. Zhu, F. Gao, J. Lian, W. J. Weber, Phys Rev B 82 (2010)184105-1-7.

[10] N. Wang, C. Zhou, S. Gong, H. Xu, J. Mater. Sci. Technol. 22 (2006) 703-797.

[11] R. Chaim, Materials Science and Engineering A 486 (2008) 439-446.

[12] A. A.Palmeira, M. J. Bondioli, K. Strecker, C. Santos, Ceramic International, 42 (2016) 2662-2669.

[13] N. P. Padture, M. Gell, E. H. Jordan,Science 296 (2002) 280-284.

[14]B. J. Wuensch, K.W. Eberman, C. Heremans, E. M. Ku, P. Onnerud, E. M.E. Yeo, S. M. Haile, J. K. Stalick, J. D. Jorgensen, Solid State Ionics 129 (2000) 111-133.

[15] R. C. Ewing, W. J. Weber, J. Lian, J. Appl. Phys. 95 (2004) 5949-5971.

[16] J. Shamblin, M. Feygenson, J. Neuefeind, C. L. Tracy, F. Zhang, S. Finkeldei, D. Bosbach, H. Zhou, R. C. Ewing, M. Lang, Nature Materials15(2016) 507-511.

[17]. J. M. Zhang, J. Lian, F. X. Zhang, J. W. Wang, A. F. Fuentes, R. C. Ewing, Journal of Physics Chemistry C 114 (2010) 11810-11815.

[18]. F. X. Zhang, J. Lian, J. M. Zhang, K. J. Moreno, A. F. Fuentes, Z. W. Wang, R. C. Ewing, J. Alloys and Compounds 494 (2010) 34-39.

[19]. J. M. Zhang, J. Lian, A. F. Fuentes, F. X. Zhang, M. Lang, F. Y. Lu,and R. C. Ewing, Appl. Phys. Lett. 94 (2009) 243110-1-3.

[20]. V. V. Rondinella and T. Wiss, Materials Today, 13 (2010) 24-32.

[21]. J. Spino, H. Santa Cruz, R. Jovani-Abril, R. Birtcher, and C. Ferrero, J. Nucl. Mater., 422 (2012) 27-44.

[22] STM E 112-88, American Society for Testing and Materials (1988). 
[23] H. C. Kim, I. Shon, I. Jeong, I. Ko, Z. A. Munir, Journal of Materials Science 42 (2007) 9409-9414.

[24] J. E. Burke, Trans Am Inst Mining MetallEng 180(1949) 73-91.

[25] J. E. Burke, E. Turnbull, Prog Metal Phys 3 (1952) 220-244.

[25] A. K. Mishra, L. Huang, Small11(2015)361-366.

[27] J. Luo, S. Adak, R. Stevens, J. Mater. Sci. 33 (1998) 5301-5309.

[28] T.G. Nieh, J. Wadsworth, J. Am. Ceram. Soc. 8 (1989) 1469-1472.

[29] N. Clavier, R. Podor, L. Deliere, J. Ravaux, N. Dacheux, Materials Chemistry and Physics, 137 (2013)742-749.

[30] G. Sattonnay, S. Moll, L. Thomé, C. Decorse, C. Legros, P. Simon, J. Jagielski, I. Jozwik, and I. Monnet, Journal of Applied Physics 108(2010) 103512-1-13.

[31] Ž. Antić, K. Prashanthi, S. Ćulubrk, K.Vuković, M. D. Dramićanin, T.Thundat, Applied Surface Science 364 (2016) 273-279.

[32] M. Maczka, J. Hanuza, K. Hermanowicz, A. F.Fuentes, K. Matsuhira, Z. Hiroi, J. Raman Spectroscopy 39 (2008) 537-544.

[33] M. Maczka, M. L. Sanju' an, A. F. Fuentes, L. Macalik, J. Hanuza, K. Matsuhira, and Z. Hiroi, Phys. Rev. B 79(2009) 214437-1-13.

[34] M. L. Sanju' an, C. Guglieri, S. D' iaz-Moreno, G. Aquilanti, A. F. Fuentes, L. Olivi, J. Chaboy, Phys Rev. B 84 (2011)104207-1-18.

[35] K.B. Helean, S.V. Ushakov, C.E. Brown, A. Navrotsky, J. Lian, R.C. Ewing, J.M. Farmer, L.A. Boatner, J. Solid State Chem. 177 (2004) 1858-1866.

[36] K.E. Sickafus, L. Minervini, R. W. Grimes,J. A. Valdez,M. Ishimaru, F. Li, K. J. McClellan,T. Hartmann,Science 289 (2000)748-754. 
[37] S. Park, M. Lang, C. L. Tracy, J. Zhang, F. Zhang, C. Trautmann, M.D. Rodriguez, P. Kluth, R. C. Ewing, Acta Materialia 93(2015) 1-11.

\section{Figure Captions}

Fig. 1(a) X-ray diffraction pattern, and (b) scanning electron micrograph of the HEBM-milling powders showing amorphous nature and typical features of micron-sized granules containing nano-sized particles.

Fig. 2 High-resolution SEM images of the $n c-\mathrm{Gd}_{2} \mathrm{Ti}_{2} \mathrm{O}_{7}$ specimens subjected to grain growth heat treatments for the duration of $4 \mathrm{~h}$ at the temperature of (a) $1300{ }^{\circ} \mathrm{C}$, (b) $1400{ }^{\circ} \mathrm{C}$, and (c) 1500 ${ }^{\circ} \mathrm{C}$. The small back dots represent the pores. The average grain size of the as-sintered sample was about 100-120 nm which was increased to tens of micron on annealing at the high temperature.

Fig. 3 High-resolution SEM images of the $n c-\mathrm{Gd}_{2} \mathrm{Ti}_{2} \mathrm{O}_{7}$ specimens prepared from nanopowders by spark plasma sintering at the temperature of $1200{ }^{\circ} \mathrm{C}$ and pressure of $40 \mathrm{MPa}$, and also annealed at $(\mathrm{a}, \mathrm{b}) 1300{ }^{\circ} \mathrm{C}$, and $(\mathrm{c}, \mathrm{d}) 1500{ }^{\circ} \mathrm{C}$ for the duration of 0.5 and 8 hours.

Fig. 4 Grain size versus grain growth temperature in the $n c-\mathrm{Gd}_{2} \mathrm{Ti}_{2} \mathrm{O}_{7}$.

Fig. 5 Curves for variation of the (a) $\left(\mathrm{G}_{\mathrm{t}}{ }^{\mathrm{n}}-\mathrm{G}_{0}{ }^{\mathrm{n}}\right)$ versus time, and (b) growth constant versus inverse temperature in nc- $\mathrm{Gd}_{2} \mathrm{Ti}_{2} \mathrm{O}_{7}$. 
Fig. 6 Representative X-ray diffraction patterns of the $n c-\mathrm{Gd}_{2} \mathrm{Ti}_{2} \mathrm{O}_{7}$ pellets prepared by sintering nano-powder at the $1200{ }^{\circ} \mathrm{C}$ and $40 \mathrm{MPa}$ for 20 minutes, and further heat treated at $1300{ }^{\circ} \mathrm{C}$ upto the duration of 8 hours.

Fig. 7 Representative Raman spectra for as-sintered, as well as samples annealed at different temperatures of $1300{ }^{\circ} \mathrm{C}, 1400{ }^{\circ} \mathrm{C}$, and $1500{ }^{\circ} \mathrm{C}$ at 4 hours. Four $\mathrm{T}_{2 \mathrm{~g}}$ modes appeared at the wavenumber of $200 \mathrm{~cm}^{-1}, 308 \mathrm{~cm}^{-1}, 316 \mathrm{~cm}^{-1}$ and $450 \mathrm{~cm}^{-1}$ are assigned to O-Gd-O bond bending; whereas, one $\mathrm{A}_{1 \mathrm{~g}}$ appeared at the wavenumber of $516 \mathrm{~cm}^{-1}$ is assigned to $\mathrm{Gd}-\mathrm{O}$ stretch.

Fig.8 Comparative Raman spectra for the samples subjected to annealing at the different durations $\left(1,2,4\right.$, and 8 hours) at (a) $1500{ }^{\circ} \mathrm{C}$, and (b) $1300{ }^{\circ} \mathrm{C}$,. The intensity ratio $\left(\mathrm{T}_{2 \mathrm{~g}} / \mathrm{A}_{\mathrm{gg}}\right)$ versus annealing time showing $\mathrm{T}_{2 \mathrm{~g}} / \mathrm{A}_{1 \mathrm{~g}}$ intensity ratio remained unchanged with increase in the annealing time.

\section{Table Caption}

Table 1: Porosity, crystallite size and micro-strain values of the sample annealed for the duration of 4 hours at (a) $1300{ }^{\circ} \mathrm{C}$, (b) $1400{ }^{\circ} \mathrm{C}$, and (c) $1500{ }^{\circ} \mathrm{C}$.

Table 2: Average grain size of the annealed $n c-\mathrm{Gd}_{2} \mathrm{Ti}_{2} \mathrm{O}_{7}$ prepared from the sintering of nanopowder

Table 3: Physical parameters for grain growth in the ceramicmaterials 


\begin{tabular}{|l|l|l|l|l|}
\hline $\begin{array}{l}\text { Table 1: Porosity, crystallite size and micros-train values of the } \mathrm{Gd}_{2} \mathrm{Ti}_{2} \mathrm{O}_{7} \text { under the condition of } \\
\text { as-sintered as well as annealed for the duration of } 4 \text { hours at (a) } 1300{ }^{\circ} \mathrm{C} \text {, (b) } 1400{ }^{\circ} \mathrm{C} \text {, and (c) } \\
1500{ }^{\circ} \mathrm{C}\end{array}$ \\
\hline $\begin{array}{l}\text { Annealing } \\
\text { temperature }\end{array}$ & As-sintered & $1300{ }^{\circ} \mathrm{C}$ & $1400{ }^{\circ} \mathrm{C}$ & $1500{ }^{\circ} \mathrm{C}$ \\
\hline Porosity (\%) & 6.0 & 5.4 & 4.7 & 3.9 \\
\hline Micro-strain & 0.24 & 0.09 & 0.11 & 0.13 \\
\hline $\begin{array}{l}\text { Crystallite size } \\
(\mathrm{nm})\end{array}$ & 83 & 149 & 485 & 2650 \\
\hline
\end{tabular}

Table 2: Average grain size of the annealed $n c-\mathrm{Gd}_{2} \mathrm{Ti}_{2} \mathrm{O}_{7}$ prepared from the sintering of nanopowder

\begin{tabular}{|c|c|c|c|}
\hline \multicolumn{4}{|c|}{ Table 2: Average grain size of the annealed $\begin{array}{c}\text { nc- } \mathrm{Gd}_{2} \mathrm{Ti}_{2} \mathrm{O}_{7} \text { prepared from the sintering of nano- } \\
\text { powder }\end{array}$} \\
\hline $\begin{array}{c}\text { Annealing } \\
\text { time (hr) }\end{array}$ & \multicolumn{3}{|c|}{$\begin{array}{c}\text { Grain size }(\mu \mathrm{m}) \\
\text { Annealing temperature }\end{array}$} \\
\cline { 2 - 4 } & $1300{ }^{\circ} \mathrm{C}$ & $1400{ }^{\circ} \mathrm{C}$ & $1500{ }^{\circ} \mathrm{C}$ \\
\hline 0 & $0.12 \pm 0.01$ & $0.12 \pm 0.01$ & $0.12 \pm 0.01$ \\
\hline 0.5 & $0.17 \pm 0.01$ & $0.32 \pm 0.02$ & $0.63 \pm 0.02$ \\
\hline 1 & $0.64 \pm 0.04$ & $1.11 \pm 0.05$ & $2.49 \pm 0.15$ \\
\hline 2 & $0.73 \pm 0.06$ & $1.44 \pm 0.18$ & $4.64 \pm 0.57$ \\
\hline 4 & $0.94 \pm 0.06$ & $1.97 \pm 0.22$ & $6.46 \pm 0.25$ \\
\hline 8 & $1.14 \pm 0.12$ & $2.27 \pm 0.51$ & $10.04 \pm 1.17$ \\
\hline
\end{tabular}

Table 3: Physical parameters for grain growth in the ceramicmaterials

\begin{tabular}{|c|c|c|c|c|c|}
\hline \multicolumn{6}{|c|}{ Activation energy for grain growth in ceramic } \\
\hline Ceramic & $\begin{array}{c}\text { Grain } \\
\text { size }\end{array}$ & $\begin{array}{c}\text { Temperature } \\
\text { range }\end{array}$ & $\begin{array}{c}\text { Activation energy } \\
(\mathrm{kJ} / \mathrm{mol})\end{array}$ & Measurements & $\begin{array}{c}\text { Grain } \\
\text { growth } \\
\text { exponent }\end{array}$ \\
\hline $\begin{array}{c}\mathrm{Gd}_{2} \mathrm{Ti}_{2} \mathrm{O}_{7} \\
\text { (Present Study) }\end{array}$ & $\begin{array}{c}100 \mathrm{~nm}- \\
10 \mu \mathrm{m}\end{array}$ & $1300-1500^{\circ} \mathrm{C}$ & $240 \pm 20$ & $\begin{array}{c}\text { Sintering } \\
\text { followed by }\end{array}$ & 2 \\
\hline
\end{tabular}




\begin{tabular}{|c|c|c|c|c|c|}
\hline & & & & annealing & \\
\hline $\begin{array}{c}\text { 3Y-TZP } \\
{[27]}\end{array}$ & $\sim 100 \mathrm{~nm}$ & $700-1400{ }^{\circ} \mathrm{C}$ & 352 & Sintering & 3 \\
\hline $\begin{array}{l}\text { YSZ } \\
{[28]}\end{array}$ & & & $\begin{array}{c}580 \text { (Static) } \\
520 \text { (Dynamic) }\end{array}$ & Super Plastic & 2 , and 3 \\
\hline YSZ [11] & $42 \mathrm{~nm}$ & $1250-1650^{\circ} \mathrm{C}$ & $\begin{array}{c}280 \pm 10(<1400 \\
\left.{ }^{\circ} \mathrm{C}\right) \\
546 \pm 22(>1400 \\
\left.{ }^{\circ} \mathrm{C}\right) \\
\end{array}$ & $\begin{array}{l}\text { Sintering } \\
\text { followed by } \\
\text { annealing }\end{array}$ & 2 \\
\hline $\mathrm{ThO}_{2}[29]$ & $\sim 50 \mathrm{~nm}$ & $1250-1400^{\circ} \mathrm{C}$ & $435 \pm 25$ & Sintering & 2 \\
\hline $\mathrm{TiO}_{2}[26]$ & $5 \mathrm{~nm}$ & $600-750{ }^{\circ} \mathrm{C}$ & $72 \pm 2$ & Annealing & 2 \\
\hline
\end{tabular}




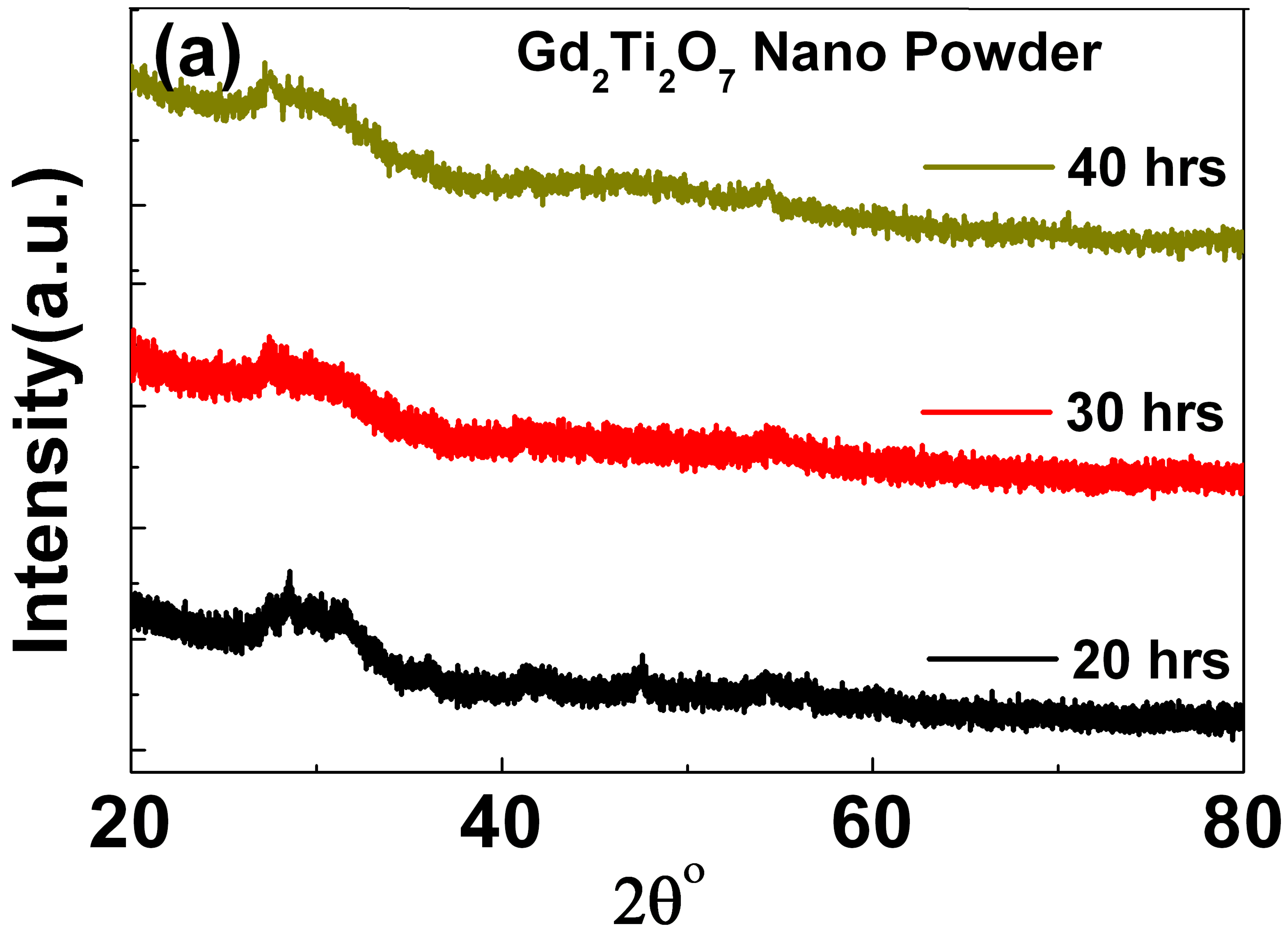




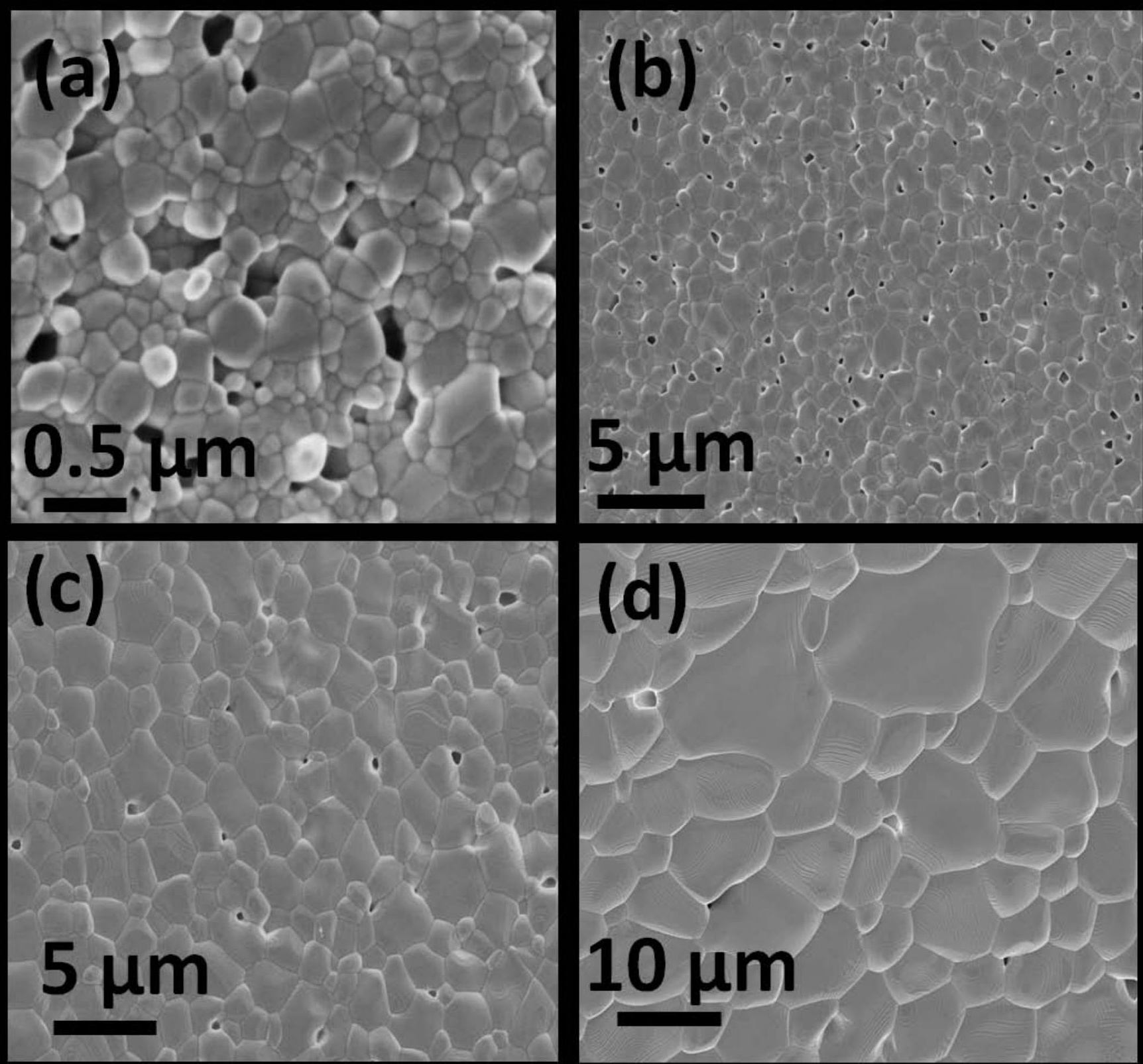




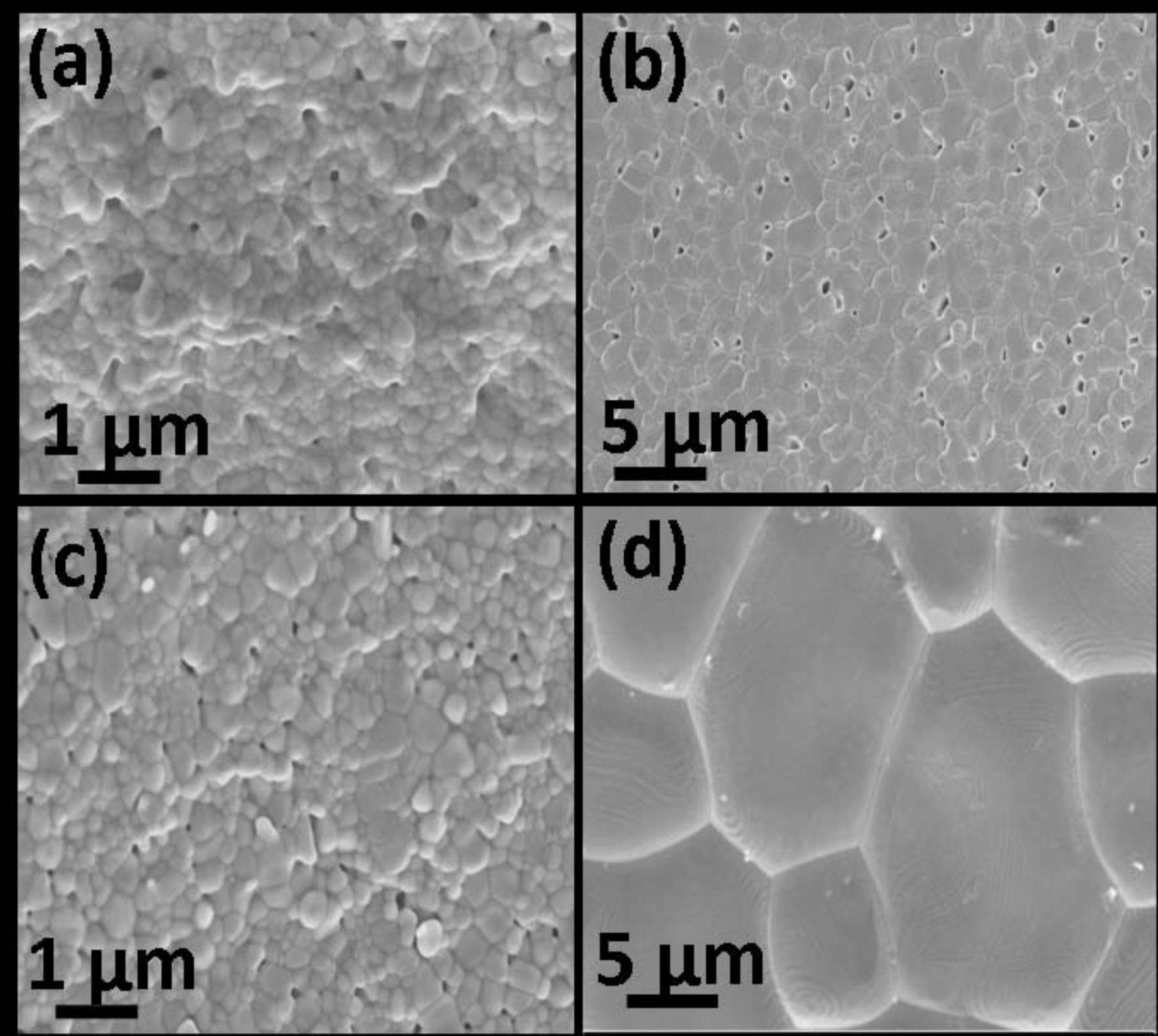




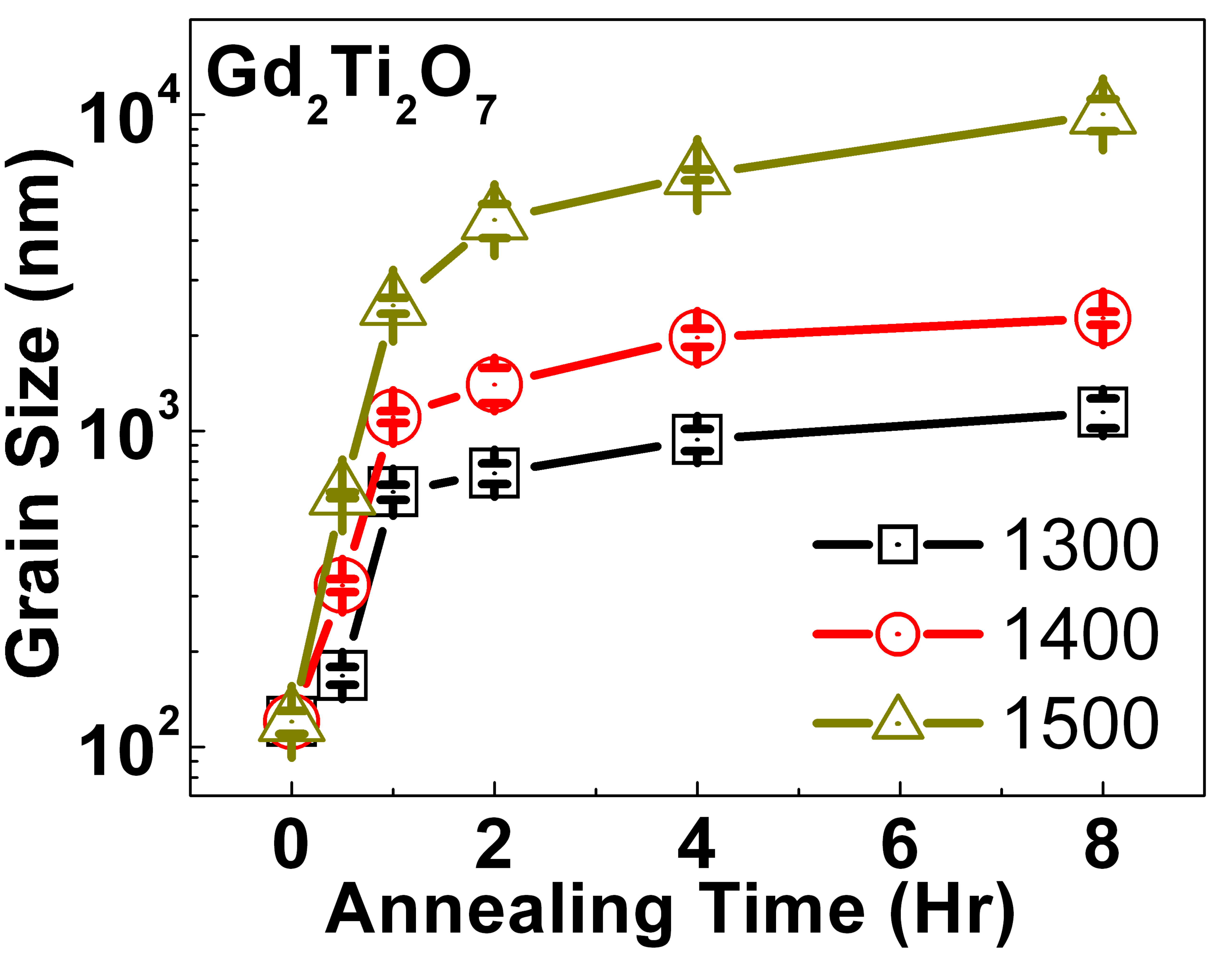




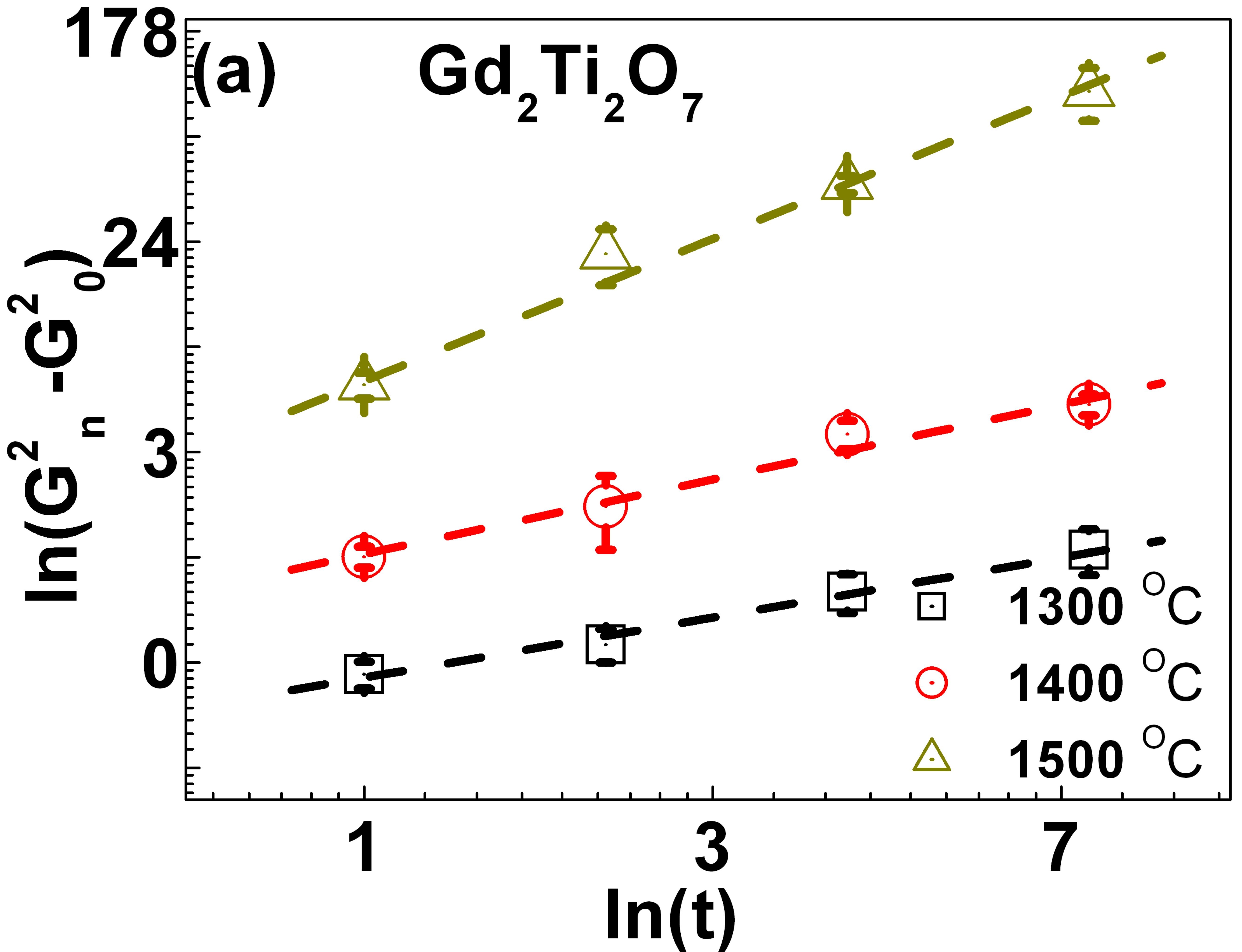




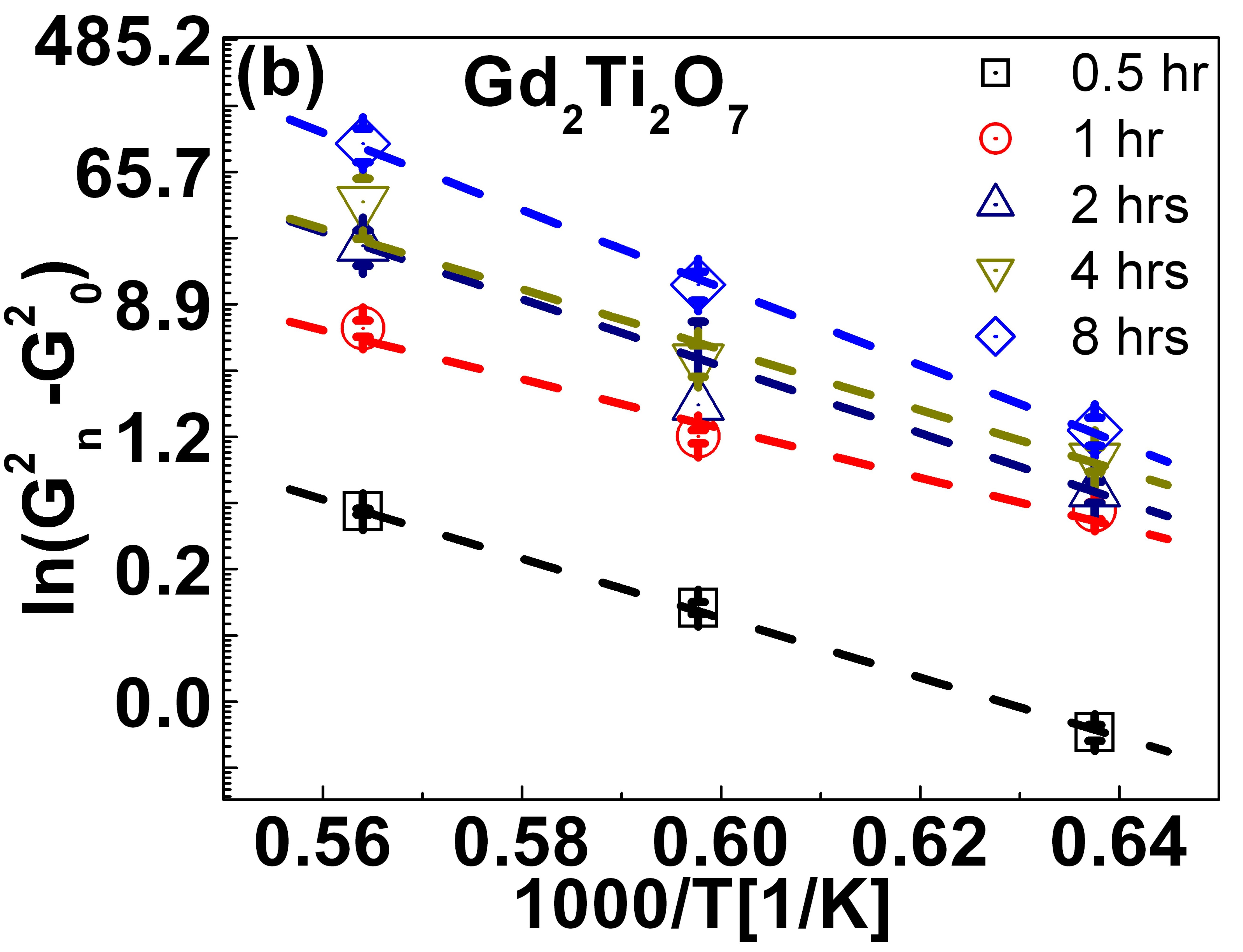




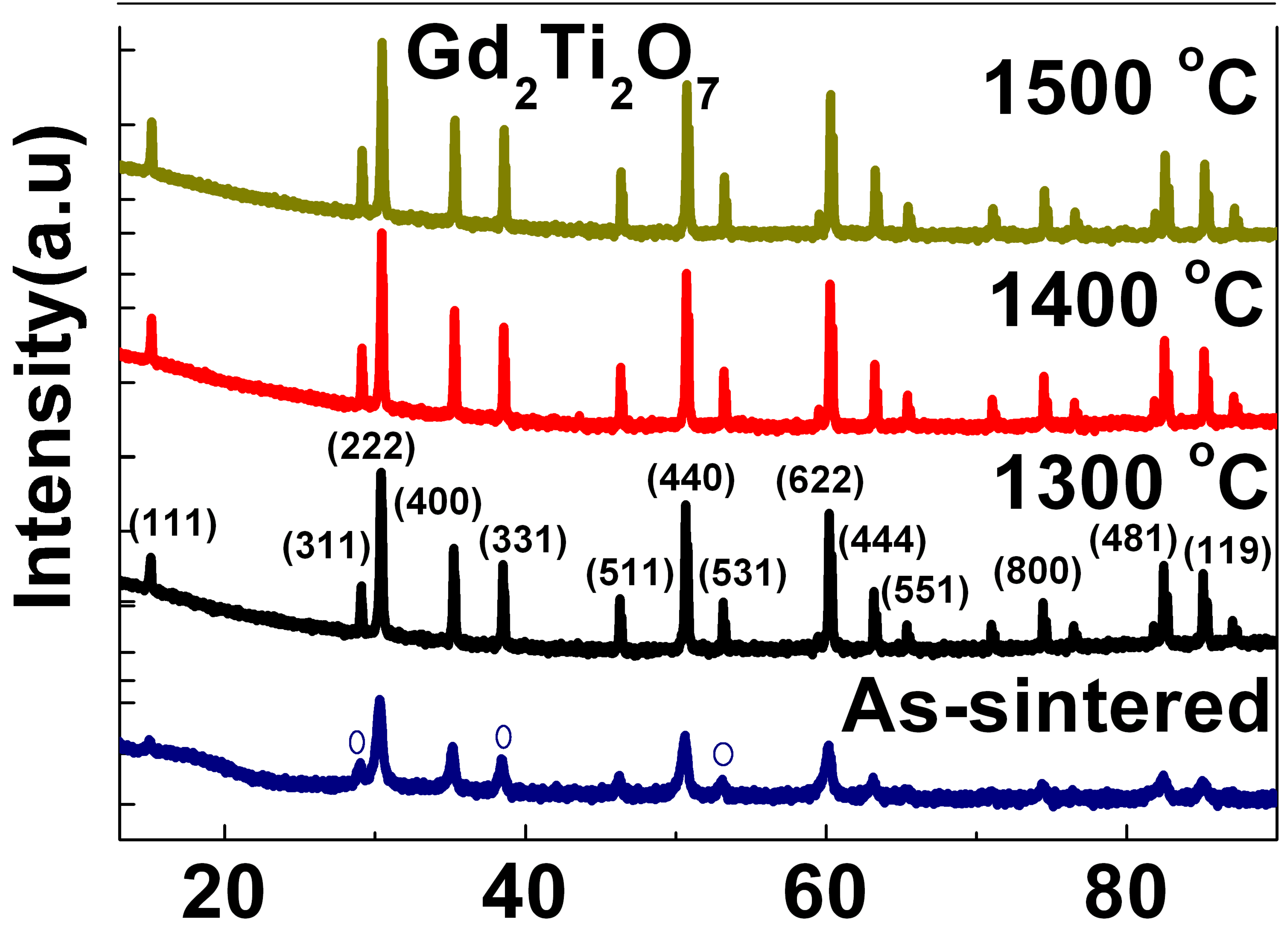




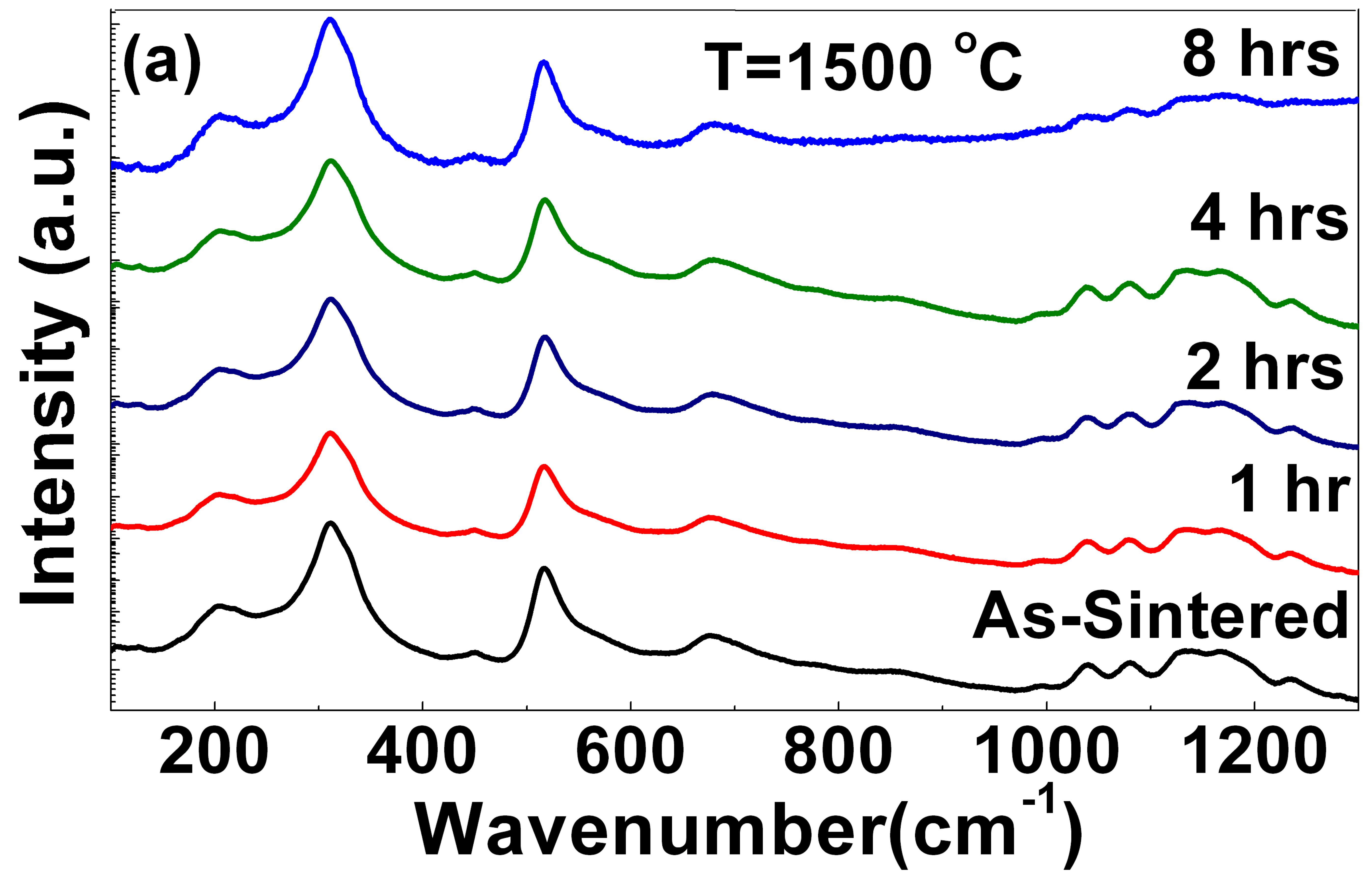




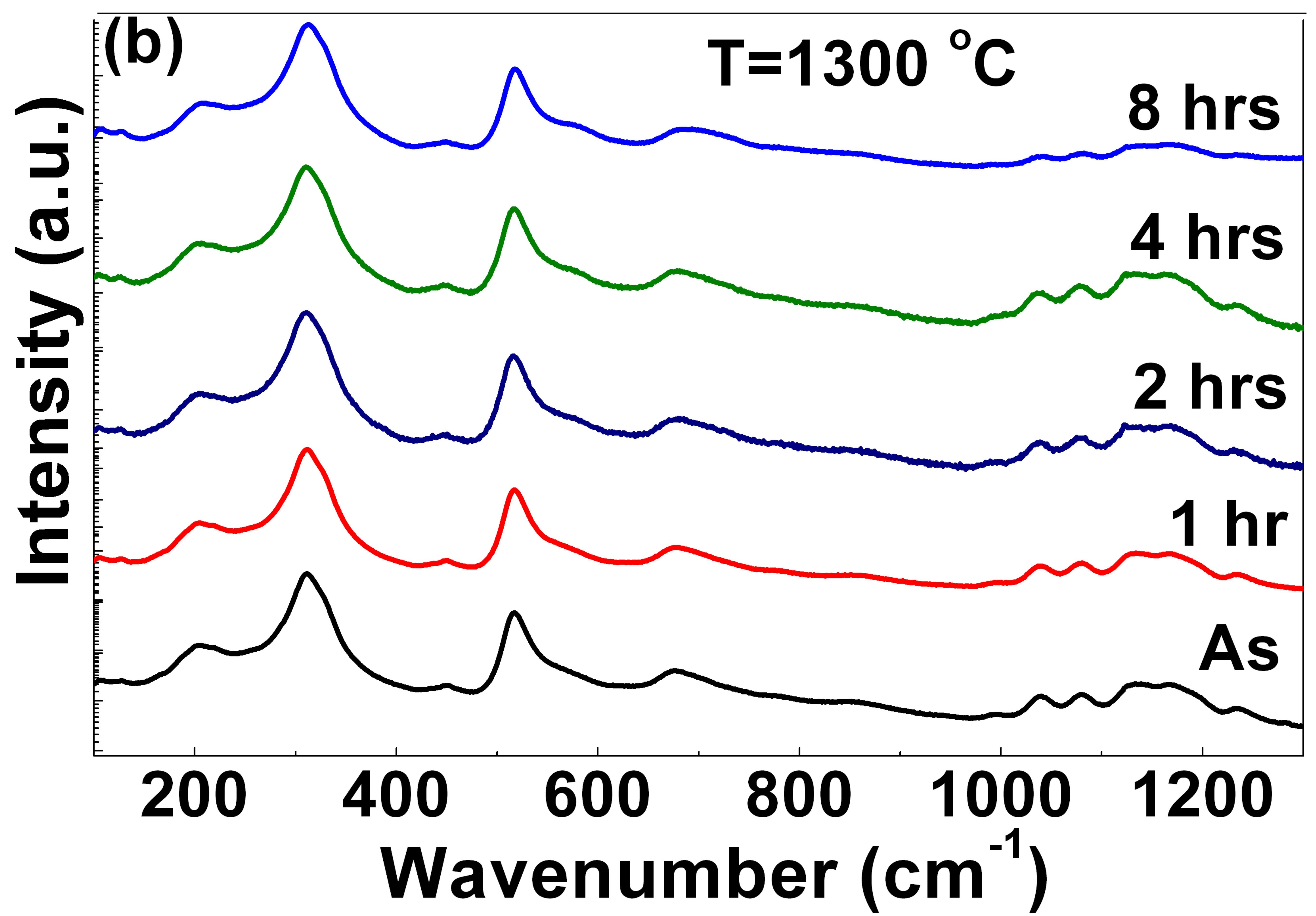

